\title{
Escotismo e esporte: propostas de educação do corpo no Rio de Janeiro dos anos 1910-1920
}

Carlos Herold Junior' Victor Andrade de Melo"

RESUMO

O objetivo neste estudo foi discutir as aproximações entre as agremiações esportivas e o escotismo no Rio de Janeiro dos anos 1910-1920. Nessas décadas, institucionalizaram-se os pioneiros grupos de scouts e, simultaneamente, as sociedades de esporte adquiriram novas conformações. Como fontes, fizemos uso de periódicos publicados na cidade e no período em tela. Foi possível perceber que, no tocante ao encontro entre os dois movimentos, o escoteiro e o esportivo, esgrimiram-se argumentos de educação do corpo articulados com o momento sociopolítico da nação.

\section{PALAVRAS-CHAVES}

escotismo; esporte; educação do corpo. 


\title{
SCOUTING AND SPORT: BODY EDUCATION PROPOSALS IN 1910-1920S RIO DE JANEIRO
}

\begin{abstract}
This study aimed to discuss the similarities between sporting clubs and Scouting in Rio de Janeiro during the years of 1910-1920. In those decades, the first scouting groups were institutionalized. Pari passu, sport societies acquired new conformations. For this work, we used as sources periodicals published in the city during this period. It was possible to realize that, relating the encounter of these two movements (scout and sport), arguments about body education in connection with the socio-political moment of the nation were waged.
\end{abstract}

KEYWORDS

scouting; sport; body education.

\section{ESCOUTISMO Y DEPORTE: PROPUESTAS DE EDUCACIÓN DEL CUERPO EN RIO DE JANEIRO DE LOS AÑOS 1910-1920}

\section{RESUMEN}

Este estudio tuvo como objetivo analizar las aproximaciones entre los clubes deportivos y el Movimiento Scout en Rio de Janeiro de los años 1910-1920. En estas décadas, se institucionalizaron los pioneros grupos de scouts. Pari passu, las sociedades deportivas adquirieron nuevas conformaciones. Como fuentes, hicimos uso de periódicos publicados en la ciudad en el período. Se pudo observar que, en lo que respecta al encuentro entre de los dos movimientos (de scouts y deportivo), se construyeron argumentos de educación del cuerpo articulados con el momento socio-político de la nación.

PALABRAS CLAVE

escultismo; deporte; educación del cuerpo. 


\section{INTRODUÇÃO}

Em outubro de 1913, um colunista de Careta — periódico que gozava de grande prestígio - comentou a rápida expansão do escotismo pelo mundo. Ele reconheceu a utilidade da iniciativa na medida em que "a instituição visa o desenvolvimento físico e moral do indivíduo, tornando-o apto para as lutas da vida" (Careta, 25 out. 1913, p. 25). Todavia, no que tange à implantação do movimento escoteiro em nosso país, o cronista mostrava-se descrente: "Não acreditamos que essa útil instituição possa se adaptar ao Brasil, terra em que o próprio governo matou as linhas de tiro em que os cidadãos se exercitavam".

A crítica colocava o escotismo em perspectiva a partir do que estava a ocorrer com o Tiro Nacional. Essa instituição, criada em 1899, oferecia instruções da prática para civis e militares, tendo em conta o aumento de preocupações com a defesa nacional e com a modernização das Forças Armadas ${ }^{1}$. O primeiro núcleo foi criado no Palácio Guanabara e o segundo,em Realengo, expressão tanto da relação dos militares com a iniciativa quanto da tentativa de espraiar pela cidade as oportunidades de aprendizado da modalidade 2 .

Nesses núcleos, o tiro esportivo melhor se estruturou. A modalidade já existia em alguns clubes fluminenses desde os anos 1870 e naquela transição de séculos acabou aglutinando discursos mais ambiciosos concernentes ao desenvolvimento da nação. Para além de uma aparente frivolidade, a expectativa era de que ele pudesse ser um contributo para que a juventude se engajasse em iniciativas de progresso do país. Vale lembrar que a Confederação do Tiro Brasileiro foi criada em 1906, ligada ao Ministério da Guerra e controlada por este.

Nos anos 1910, o Tiro Nacional tinha se enfraquecido, ainda que a modalidade esportiva tenha continuado seu processo de estruturação com a fundação de agremiações específicas (como o Revólver Clube) e criação de novos stands, entre os quais o do Fluminense Futebol Clube. Nessas experiências surgiram atletas brasileiros de destaque, como Guilherme Paraense e Afrânio Antônio da Costa, medalhistas nos Jogos Olímpicos da Antuérpia (1920)3 ${ }^{3}$, considerados heróis da nação por suas conquistas 4 .

Essas iniciativas eram de alcance limitado e incomodava o cronista de Careta o fato de que fracassara o intuito de vulgarização da prática do tiro para o grande conjunto da população. Da mesma forma, passava por dificuldades uma experiência pioneira com o escotismo, que estava então em curso. Em junho de 1910, fora fundado, por membros da Marinha, o Centro de Boys Scouts do Brasil ${ }^{5}$, com sede, à época, no ainda bucólico bairro do Catumbi ${ }^{6}$ (Figura 1).

1 Para mais informações, ver Carvalho (2005).

2 Para mais informações, ver Melo e Peres (2016a).

3 Para mais informações, ver Melo (2015) e Melo e Peres (2016a).

4 Para mais informações, ver Melo e Peres (2016b).

5 A notícia de fundação do Centro pode ser encontrada em Correio da Manhã (19 jun. 1910, p. 4). Ver interessantes relatos em Blower (1995) e Borba (1992), este último um artigo sobre Benjamin Sodré, oficial de Marinha, um dos líderes do desenvolvimento do escotismo no país, também esportista envolvido com importantes movimentos de conformação do campo esportivo nacional. Para mais informações, ver Herold Junior (2015).

6 Depois foi estabelecida outra sede na Sociedade Propagadora de Instrução, na Ponta do Caju (A Imprensa, 02 abr. 1911, p. 1). 
Nessa primeira experiência, até mesmo pela relação que havia entre o movimento escoteiro e as iniciativas de "regeneração da juventude", as práticas esportivas já integravam o programa de atividades. Em entrevista concedida ao Correio da Manhã, Floriano Reis, um dos primeiros integrantes do Centro de Boys Scouts, recordou que nas reuniões, realizadas no Observatório da Escola Politécnica (Morro de Santo Antônio), praticavam-se boxe, esgrima, equitação e natação (Correio da Manhã, 11 dez.1925, p. 10). De fato, no programa de intenções apresentado por ocasião da fundação do Centro, publicado no Correio da Manhã (19 jun. 1910, p. 4), já se sugeriu que seria "uma sociedade de instrução, diversões e esporte". Entre seus fins, apresentava-se a oferta de aulas de "tiro ao alvo, esgrima, ginástica e jogos atléticos".

Engajados nas preocupações com o futuro da nação, entre os primeiros escoteiros a prática do tiro, com as caminhadas, foi uma das mais usuais, tendo em vista o intuito de formar "soldados aptos, inteligentes e fortes que amanhã defenderão a Pátria” (O Malho, 12 nov. 1911, p. 8). Não surpreende que uma tropa escoteira de curta duração (1912-1915) tenha sido criada no Tiro de Guerra 102, de Realengo, antigo núcleo do Tiro Nacional. Com efeito, durante décadas as atividades físicas e esportivas fizeram parte do programa cotidiano de vários grupos de scouts (Figura 2).

$\mathrm{O}$ intuito de contribuir para a formação da juventude aproximava o escotismo e o campo esportivo. Há de se ter em conta que tal encontro se fortaleceu em virtude de o esporte receber novos olhares e interpretações. Se de início era considerado eminentemente um jogo (tendo como grande representante o turfe), desde o quartel final do século XIX passara a ser encarado como uma escola de virtudes (a modalidade-exemplo era o remo) (Melo e Peres, 2015). Naqueles anos 1910, mais do que nunca, passou a ser compreendido como uma das estratégias

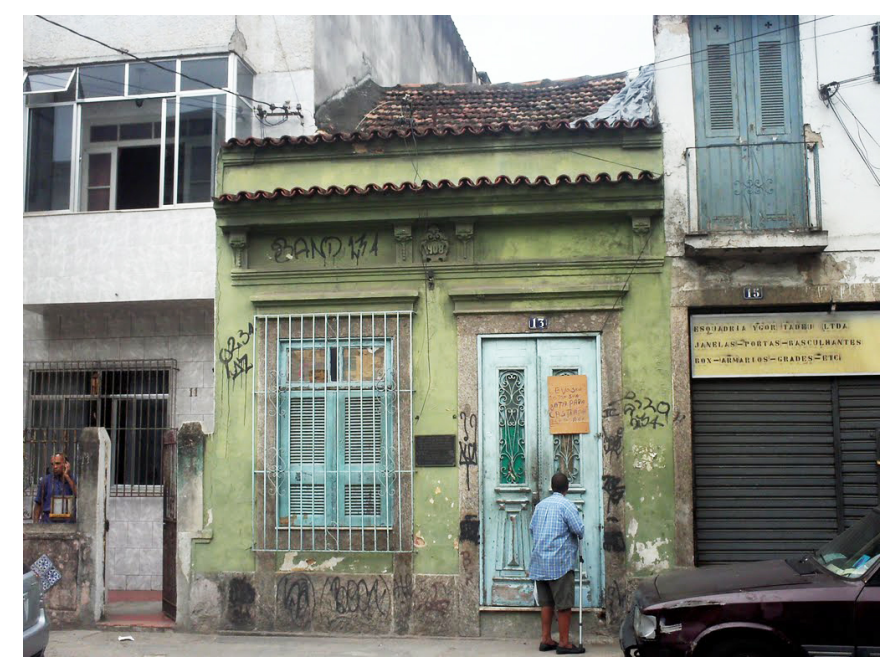

Figura 1 - Antiga sede do Centro de Boys Scouts do Brasil, bairro do Catumbi, Rio de Janeiro.

Disponível em: <http://mapio.net/pic/p-60554102/>. 
para o desenvolvimento da nação. Além de passar a ser tido como um meio eficaz de intervenção no corpo infantil e juvenil, a participação em competições internacionais começava a ser representada como um indicador da grandeza nacional (Melo e Peres, 2016b).

Essa constatação nos ajuda a entender o fato de as atividades escoteiras, frequentemente, serem tratadas como modalidade esportiva. Sobre uma caminhada realizada pelos Boys Scouts, em novembro de 1910, comentou um cronista: "É um dos esportes que merecem rasgados elogios. Os meninos que se habituam a vencer grandes distâncias a pé, não só se desenvolvem e consolidam a saúde, mas ficam preparados para bons defensores da pátria” (O Tico-Tico, 05 abr. 1911, p. 28).

Em certas ocasiões, o próprio movimento escoteiro foi encarado como um sport. Um cronista de $O$ Imparcial sugeriu que "o escotismo deve ser considerado o esporte preliminar, o abc dos esportes, a primeira preparação física e moral da juventude para a vida" (O Imparcial, 12 fev. 1914, p. 5).Para Atilio Vivacqua, um dos pioneiros defensores e divulgadores do movimento, "sistema baseado num fundo esportivo completo, o escotismo é um preparo e uma emulação para o exercício da disciplina e solidariedade" (O Imparcial, 04 jan. 1917, p. 2).

Não surpreende, dessa maneira, que os clubes esportivos tenham começado a se envolver com o escotismo. Como se deu tal encontro? Que discursos marcaram tal relacionamento? Este estudo teve por objetivo discutir as aproximações entre agremiações esportivas e o movimento escoteiro no Rio de Janeiro das décadas 1910-1920, momento em que se institucionalizaram os pioneiros grupos scouts e quando as sociedades de esporte adquiriram, mais claramente, novas conformações.

Para alcance do objetivo, interessados nos discursos esgrimidos pelos envolvidos com os dois movimentos (esportivo e escoteiro) e pela imprensa (considerando sua importância na repercussão pública dos grandes temas

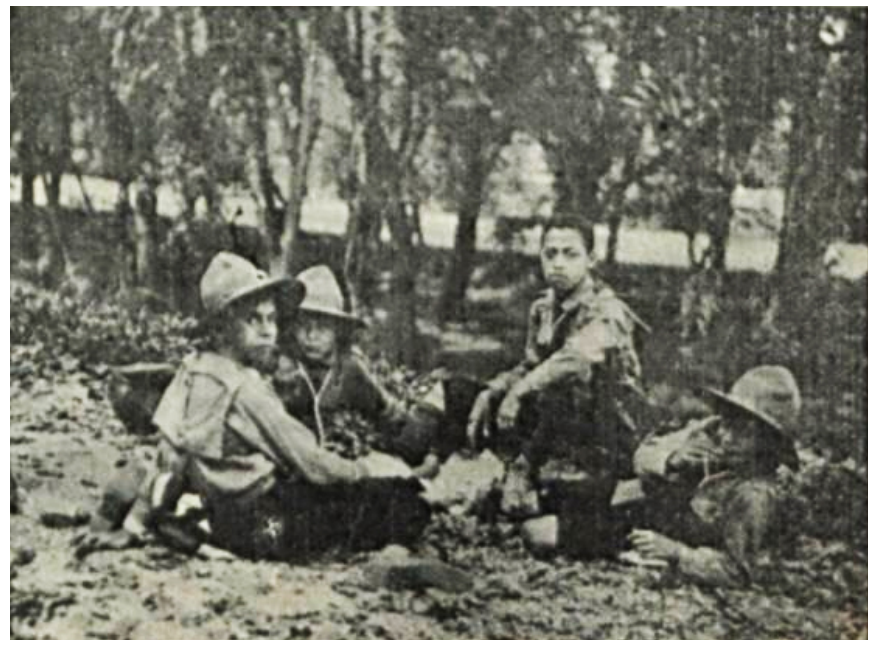

Figura 2 - Provavelmente primeira imagem dos escoteiros brasileiros publicada na imprensa. Fonte: O Malho (17 set. 1910, p. 43). 
do momento), utilizamos como fontes periódicos publicados na cidade do Rio de Janeiro no período em tela ${ }^{7}$. O que queremos perceber é como, no encontro dos dois movimentos, circularam e se complementaram argumentos de educação do corpo, articulados com o momento sociopolítico da nação.

Nosso intuito foi prospectar estratégias pedagógicas que se concebiam extrapolando o âmbito escolar, ainda que com esse também se articulassem. Vale ter em conta que, naquele momento, também nas instituições escolares públicas e privadas, o escotismo estava a ser considerado e implantado. Além disso, já havia reflexões sobre o potencial pedagógico do esporte ${ }^{8}$ e sobre a necessidade de sua introdução nas escolas.

As décadas de 1910 e 1920 foram plenas de problemáticas urgentes para o país. As propostas republicanas não conseguiam se implementar plenamente, gerando grande tensão no âmbito da política, prenunciando o esgarçamento de alianças que culminaram na Revolução de 1930. Do ponto de vista da economia, se de um lado o país sentia o efeito tanto dos conflitos mundiais quanto das crises financeiras internacionais, de outro lado também se preparava para consolidar o processo de diversificação de sua base produtiva e comercial. Socialmente, marcava o momento a melhor consolidação de diferentes estratos, entre os quais os trabalhadores, que se organizavam e participavam ativamente de variados movimentos. De igual modo, as mulheres galgavam mais visibilidade, à esteira do que já vinha ocorrendo desde as décadas finais do século XIX. Culturalmente, deve-se destacar a maior estruturação de um mercado de entretenimentos e a sua conexão com o cenário internacional, notadamente, com os Estados Unidos, país que começava a substituir a Europa como padrão de influência 9

Para abordar esse contexto e os indícios utilizados neste trabalho, levamos em consideração a importância da experiência corporal no estudo da história educacional a partir do que propõe Georges Vigarello (2003). Ao analisarmos a convergência do esporte e do escotismo na cidade do Rio de Janeiro no período, é possível perceber a existência de "três grandes faces da existência corporal" (Vigarello, 2003, p. 22). A educação do físico diz respeito ao ensino de certas técnicas, certas formas consideradas "corretas" de uso do corpo, o que é definido pelo autor como "princípio da eficácia". A educação do espírito tem a ver com um conjunto de comportamentos encarados como socialmente adequados para a escavação de um "território totalmente pessoal, ou seja, apropriação no mais íntimo de si, nos limites de sua dimensão biológica" (Vigarello, 2003, p. 22). Isso é chamado pelo historiador francês de "princípio da propriedade". Já o que ele chama de "princípio da identidade" considera as necessidades de consolidação da sociedade civil e da nação, a inserção do indivíduo, de forma "segura", em coletivos maiores ${ }^{10}$.

7 Para trato do material, tivemos em conta as sugestões de Luca (2005).

8 Para um olhar sobre como esporte passou a ser considerado no âmbito das discussões educacionais, ver Linhales (2009).

9 Para um panorama do período, ver Ferreira e Delgado (2003).

10 Para um olhar semelhante sobre a educação do corpo, ver Soares (2001). 
Nesse sentido, tanto o esporte quanto o escotismo serão tomados como práticas a promoverem "pelo corpo, [...] uma interiorização ou um pertencimento que designa o sujeito, ou seja, o recurso de mensagens e de trocas a partir de sinais e de expressões de natureza física"(Vigarello,2003,p.22). Por essa razão, analisaremos como o encontro entre práticas esportivas e escoteiras nos clubes cariocas das décadas de 1910 e 1920 se realizou na divulgação de "manifestações de prazer e de dor"(Vigarello, 2003, p. 22), fundamentais para a concretização de uma educação corporal atrelada a discursos de natureza sociopolítica circulantes no período (Figura 3).

No bojo das mudanças pelas quais passava a sociedade brasileira, a educação a ser obtida no e pelo corpo se tornou uma necessidade urgente, enfatizando percepções que vinham se estabelecendo desde meados do século XIX: a saúde, a higiene, a disciplina, a correção, voltadas ao desenvolvimento de posturas cívicas ${ }^{11}$. Sem que lograssem alcançar plenamente tais intuitos - em certa medida contraditórios com a própria natureza efusiva e excitante do momento - as atuações dos movimentos escoteiro e esportivo foram perspectivadas como contributos relevantes.

Para organizar nossas análises e interpretações, dividimos o texto em dois momentos: no primeiro, apresentamos as variadas maneiras de aproximação entre o escotismo e os clubes esportivos no período estudado. No segundo, são estudados tanto os discursos produzidos no seio de ambos quanto aqueles sobre eles produzidos.

\section{CLUBES ESPORTIVOS E GRUPOS ESCOTEIROS: DIVULGANDO A EFICÁCIA DAS PRÁTICAS}

No Rio de Janeiro, depois da experiência pioneira do Centro de Boys Scouts do Brasil, uma iniciativa escoteira melhor estruturada se deu com a criação de uma

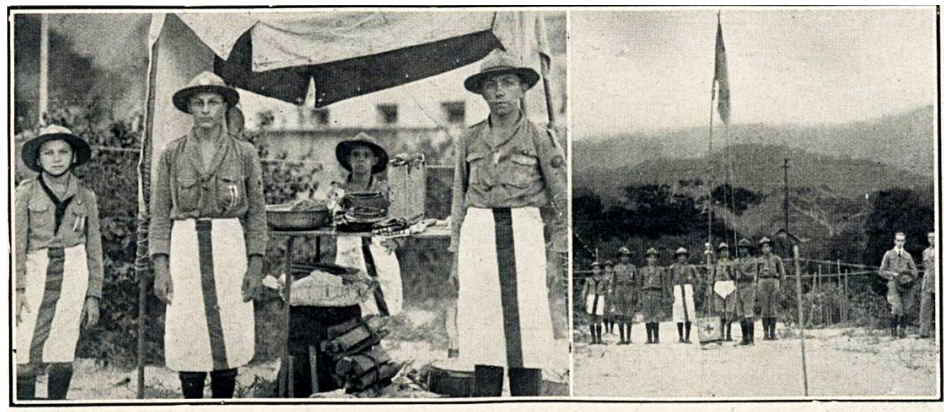

Cosinha $e$ ambulancia no. acampanento do Leblon

Figura 3 - Escoteiros em acampamento no Leblon.

Fonte: O Malho (22 abr. 1922, p. 30).

11 Deve-se ter em conta que tais preocupações foram enfatizadas com a estruturação de organizações eugênicas no Brasil (Stepan, 2004), que tiveram forte influência no debate educacional (Dávila, 2006). 
tropa em uma das mais importantes agremiações esportivas da cidade e do país no início do século XX: o Fluminense Futebol Clube. Fundada em 1916, contou com o apoio de Arnaldo Guinle e Guilhermina Guinle, personagens influentes da política e da economia nacionais.

Um dos notórios entusiastas da iniciativa foi Coelho Neto, que via muitas similaridades entre o esporte e o escotismo no que tange à preparação da juventude que conduziria a nação ao progresso, uma das bandeiras que marcou sua atuação pública. Não surpreende saber que os escoteiros do Fluminense fizessem aulas de ginástica, boxe e natação (Fernandez, 2011). Na introdução de um dos primeiros livros sobre o movimento publicado no país, em 1922, de autoria de Arnaldo Guinle e Mário Pollo, Coelho Neto reconheceu o escotismo como uma "escola" da qual saíam "seres de tempera viril tão úteis na paz pelo que aprendem brincando, como serão bravos na guerra pela resistência que adquiriram no corpo com os exercícios" (Coelho Neto, 1922, p. 5) $)^{12}$.

Por ocasião da criação da tropa, um cronista da Gazeta de Notícias exaltou a novidade. Ele sugeriu que o clube dava um passo à frente dos congêneres, aproveitando o potencial de suas instalações, inclusive o estande de tiro que estava a ser construído. Mais ainda, lembrou que o Fluminense comunicava o desejo de envolver outras agremiações esportivas do Rio de Janeiro no desenvolvimento do movimento escoteiro, o que enalteceria a sua gloriosa trajetória (Gazeta de Notícias, 03 set. 1916, p. 7). Para o colunista de A Rua, "é mais um serviço relevante que nossa Capital deve a essa sociedade em que se cultua a saúde pela força" (A Rua, 24 set. 1916, p. 1).

Há de se ter em conta que o Fluminense adotava uma estratégia de "consolidação de uma determinada identidade regional, calcada na elegância, sofisticação e riqueza” (Fernandez, 2016, p. 17). Buscava conformar uma imagem mais elitista, sempre procurando afirmar seus compromissos para com a nação. Suas lideranças comumente envolviam o clube em grandes eventos do país.

Devemos observar que os comentaristas pouco citaram as experiências anteriores do escotismo no Rio de Janeiro, o que pode ser um indicador do alcance limitado da pioneira iniciativa. De outro lado, não foram encontradas, nos anos 1910, muitas referências às atividades da tropa do Fluminense, enquanto foi possível perceber que o movimento se organizou crescentemente na cidade, inclusive com a fundação de grupos em vários bairros, além do estabelecimento de uma superintendência municipal dos escoteiros, a cargo do celebrado capitão Antonio Freire de Vasconcellos.

Qual foi o alcance do funcionamento do grupo de escoteiros do clube tricolor? Segundo Fernandez (2016), só a partir de 1920 começou a atuar efetivamente. De toda forma, antes disso, em mais de uma ocasião foi feita referência

12 Arnaldo Guinle e Mario Pollo já tinham produzido uma compilação de obras inglesas e francesas a qual denominaram "Livro do escoteiro", com apresentação de Olavo Bilac e Coelho Neto (ver Jornal do Brasil, 05 jun. 1917, p. 8). Os livros "Escotismo", de Atilio Vivacqua, e "Guia Brasileiro do Escotismo", de Hilário Freire, foram lançados na segunda metade da década de 1910 . 
à iniciativa. Por exemplo, em almoço oferecido a Arnaldo Guinle, exaltou-se sua responsabilidade pelo fato de o Rio de Janeiro ter um "grêmio de escotismo, escola de civismo e patriotismo que educa para a paz e para a guerra" (O Paiz, 23 mar. 1918, p. 10).

Além disso, dirigentes do clube estiveram envolvidos em algumas iniciativas de estruturação do movimento na cidade. Por exemplo, em 1917, Arnaldo Guinle e Mario Pollo assumiram cargos na direção da Associação Brasileira de Escoteiros no Rio de Janeiro, iniciativa que partiu da Liga de Defesa Nacional e foi endossada pelo Ministério da Guerra ${ }^{13}$. Esteve também presente na reunião de fundação dessa entidade Silvério Barbosa, representando o Botafogo Futebol Clube (O Paiz, 05 jun. 1917, p. 6). Ainda que essa agremiação demorasse mais alguns anos para ter sua seção de escotismo, trata-se de mais um indicador de que o tema chamava a atenção das sociedades esportivas.

A dar ainda mais evidência dessa atenção, deve ser mencionado que o Fluminense chegou a receber, provisoriamente, terrenos do Morro da Viúva e arredores, cedidos pelos Ministérios da Guerra e da Marinha, para as atividades de seu grupo de escoteiros (Correio da Manhã, 07 out. 1916, p. 5). De toda forma, por motivos diversos alegados - notadamente o processo de reforma pelo qual passou a sede para a construção do estádio que abrigou o Campeonato SulAmericano de Futebol de 1919, somente no final da década o clube anunciou que iria definitivamente fazer funcionar sua seção de escotismo, liderada pelo capitão Paes Brasil (Correio da Manhã, 10 dez. 1919, p. 5).

Graças à ação de lideranças como Arnaldo Guinle, Mario Pollo e Coelho Neto, e ao fato de o clube se consolidar como um dos principais do país, na década de 1920 a tropa de escoteiros do Fluminense adquiriu grande organização e protagonismo na cidade. Até mesmo em função de possuir belas e cada vez melhores instalações no bairro das Laranjeiras, a agremiação acolheu diversos eventos do movimento (como já o fazia no campo esportivo, sediando importantes campeonatos nacionais e internacionais). Por exemplo, em 1923, recebeu 24 grupos (cerca de 1.200 participantes) para comemorar o Dia do Escoteiro (A Noite, 24 nov. 1923). Em virtude da importância da iniciativa do Fluminense, a primeira referência de uma experiência escoteira promovida em um clube esportivo é pouco citada. Trata-se da criação, em 1915, de uma patrulha no Tijuca Tênis Clube liderada por Fernando Soledad, considerada pelos cronistas como um louvável e patriótico empreendimento (O Tico-Tico, 22 dez. 1915, p. 12). Outra agremiação que pioneiramente instalou um grupo de escoteiros foi o São Cristóvão Atlético Clube, em 1916. Por seu compromisso com a "educação física da mocidade" (Jornal do Brasil, 23 fev. 1916, p. 10), foi muito elogiada sua "escola de escotismo".

$13 \mathrm{O}$ envolvimento dessas duas instituições é mais um indicador de como o tema se cruzava com questões nacionais. Chegou a se discutir o quanto militar era o movimento escoteiro e se ele seria suficiente para substituir a proposta de introdução do serviço militar obrigatório. Mais ainda, foi apresentado como alternativa para evitar a militarização das escolas. Para mais informações, ver Herold Junior e Vaz (2015). 
Em 1918, por ocasião da realização do $1^{\circ}$ Congresso Fluminense de Desportos Terrestres, o escotismo chegou a ser um dos temas tratados (O Paiz, 11 ago. 1918, p. 12). Além disso, vale registrar que equipes de scouts passaram a disputar o campeonato infantil de futebol (O Tico-Tico, 26 dez. 1917, p. 11). É, contudo, somente na década seguinte que se intensificou o relacionamento entre o movimento escoteiro e o campo esportivo.

Em 1922, o Botafogo Futebol Clube criou sua seção de escotismo, liderada por um dos mais importantes nomes do movimento no Rio de Janeiro e no Brasil, o oficial de Marinha Benjamin Sodré. Entre 1921 e 1923, iniciativa semelhante houve no Clube de Regatas Flamengo, conduzida por Faustino Esposel e pelo também militar da Armada Gabriel Skiener (O Imparcial, 04 abr.1921,p. 8; A Rua, 28 jun. 1923) (Figura 4).

Em 1926, foi a vez do Vasco da Gama abrir sua seção de escotismo. Numa notícia do ano seguinte, sobre uma confraternização entre escoteiros, percebemos que o Tijuca Tênis Clube mantinha também uma patrulha (O TicoTico, 03 ago. 1927, p. 14). Não sabemos se era a continuidade da iniciativa de 1915, pois era usual que as experiências escoteiras tivessem interregnos em função de questões conjunturais (como redução do interesse ou perda, por motivos diversos, das lideranças).

Duas outras sociedades esportivas criaram suas seções de escotismo, o Esporte Clube Mangueira (em 1924) (A Noite, 16 out. 1927, p. 7) e o América Futebol Clube (em 1926) (Correio da Manhã, 29 jan. 1926, p. 6). Há, ainda, o curioso caso do Olaria Atlético Clube. Existia uma tropa mais antiga no bairro (O Tico-Tico, 17 jan. 1923, p. 16), mas somente em 1927 se comunicou que foi inaugurado um grupo na agremiação (A Noite, 24 fev. 1927, p. 7).É possível que se tratem das mesmas iniciativas ou que, ao menos, compartilhassem espaços em

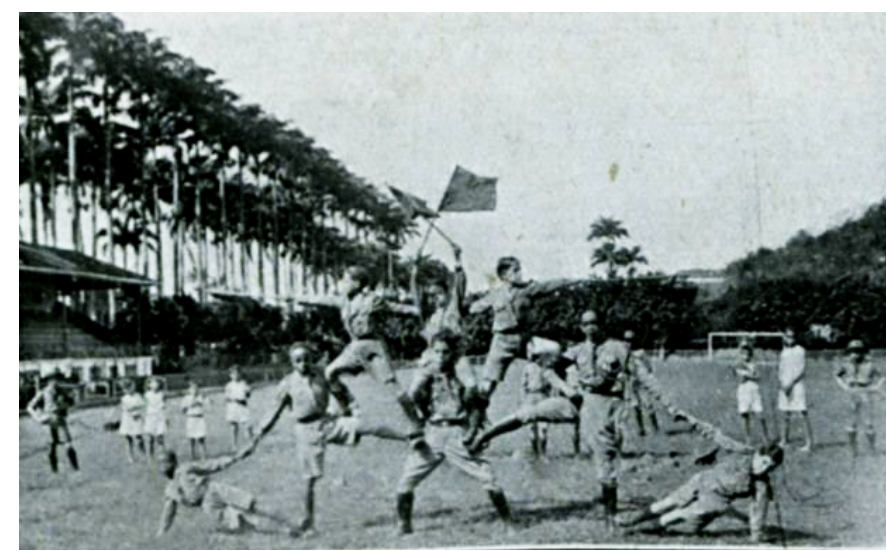

Figura 4 - Exercícios ginásticos na cerimônia de inauguração da seção de escotismo do Clube de Regatas do Flamengo. Na época, a sede era o terreno alugado do Paissandu Atlético Clube, localizado na esquina da Rua Guanabara (atual Pinheiro Machado) com Rua Paissandu.

Fonte: O Malho (13 out. 1923). 
comum, especialmente a Praia de Maria Angu, onde havia um porto ${ }^{14}$. De toda forma, vale destacar que até os dias de hoje o clube traz no seu símbolo a referência aos escoteiros do mar (Figura 5).

Vimos que os escoteiros praticavam esportes e atividades físicas em geral. Alguns grupos chegaram a instalar seções específicas para modalidades ${ }^{15}$. Além disso, havia competições internas nas tropas, especialmente nas sediadas em agremiações esportivas. Em uma delas, em 1925, o Fluminense organizou provas de natação e voleibol (O Paiz, 15 mar. 1925, p. 13). Chegou até mesmo a haver campeonatos próprios, como o Torneio de Futebol organizado pela Federação de Escoteiros do Brasil (O Tico-Tico, 09 nov. 1927, p. 21).

Enfim, em vários sentidos aumentou a intensidade do relacionamento entre o movimento escoteiro e o campo esportivo.

\section{CORPOS INDIVIDUAIS EM TORNO DE DISCURSOS EM COMUM}

Associar as práticas escoteiras aos sports não foi algo que marcou apenas o cotidiano dos grupos existentes nos clubes esportivos. Responsáveis pela condução do escotismo frequentemente pensaram essa relação. Nas atas do I e II Congressos Escoteiros do Brasil, que aconteceram em 1922 e 1923, é possível verificar os esforços de dirigentes e líderes de agrupamentos em buscar a "maneira correta" de estimular a prática de esportes no dia a dia das tropas (Herold Junior e Vaz, 2016).

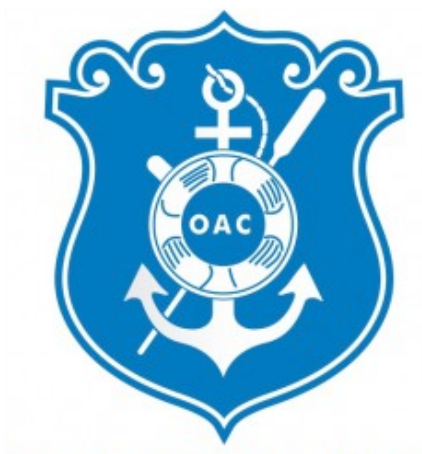

Olaria Atlético Clube

Sede: Rua Bariri, 251 - Olaria - Zona lorte do Rio (RJ) Fundada no dia $1^{2}$ de Julho de 1915

Figura 5 - Símbolo do Olaria Atlético Clube.

14 Para mais informações, ver: <https://historiadoesporte.wordpress.com/2015/10/09/ charadinha-esportiva-3-outubro-de-2015/ $\geq$. Acesso em: 26 dez. 2016.

15 Por exemplo, em 1923, os grupos de Jacarepaguá e Olaria introduziram a equitação, enquanto os de Paula Freitas e Méier criaram equipes de ciclismo (O Tico-Tíco, 16 mai. 1923, p. 17). 
De modo igualmente visível, os jornais fluminenses constantemente elogiaram esses encontros entre o movimento escoteiro e o esporte. Ao divulgar as atividades que aconteciam no América Futebol Clube, um cronista observou o "entusiasmo das reuniões":

Às crianças do bairro, embora não pertençam a famílias de sócios do clube, é facultado inscreverem-se como escoteiros e, mesmo sem inscrição, poderão ouvir as conferências. [...]. Aos sócios do clube, encarece a diretoria a necessidade e grandes vantagens da matrícula de seus filhos e parentes no grupo de escoteiros. (A Noite, 14 abr. 1926, p. 7)

Em 1927, quando foi anunciada a criação de grupo escoteiro no Olaria, sugeriu um cronista que a iniciativa muito elevaria "os créditos deste simpático e disciplinado grêmio perante os demais clubes desta capital”. A seu olhar, a repercussão era notável:

Procurando engrandecer o nome já glorioso do clube, e cultivar o espírito da nossa mocidade de hoje, para que a nossa pátria conte com homens capazes de garantirem o seu futuro, a diretoria e a comissão escolhida fazem apelo ao numeroso quadro social deste clube a fim de prestar o máximo auxílio a esta instituição, com a qual muito lucrará o clube, o esporte e o nosso grande e amado Brasil. (A Noite, 24 fev. 1927, p. 7)

Semelhantemente, um cronista de O Imparcial, ao comentar as atividades do grupo de escoteiros do Flamengo, afirmou: "a mocidade presente está disposta a, comcarinho e solicitude, aprender as lições que lhes sejam ditadas, procurando cada vez mais educar o seu físico que, como nenhum outro, tem a qualidade natural de, com ótimos resultados, receber o mais perfeito e o mais sólido preparo"(O Imparcial, 04 abr. 1921, p. 8).

Ao elogiar a intenção de se criar uma seção de escotismo no Flamengo, advogaram-se as vantagens do movimento "como meio de desenvolvimento físico e moral", enaltecendo a agremiação por compreender "a sua responsabilidade, de clube sempre na vanguarda de seus congêneres" (Correio da Manhã, 20 jan. 1920, p. 7). Alguns anos depois, ao valorizar tal iniciativa, outro articulista fez uma importante advertência. Chamou a atenção para a necessidade de não confundir, mas sim estabelecer diálogos entre os movimentos esportivo e escoteiro:

Igualmente não são todas as tropas escoteiras que praticam o verdadeiro escoteirismo, aquele que conduz a perfeição, aquele que conduz à perfeição moral, aquele que utilmente se ocupa da educação moral e que é o ideado pelo seu grande fundador, o general Baden-Powell. Tropas há, infelizmente, que são meros batalhões infantis, aulas de ginástica, clubes desportivos. $\mathrm{E}$ de pouco mais se ocupam. (Correio da Manhã, 23 out. 1923, p. 2)

A tropa do Fluminense era das mais exaltadas. Em 1920, o cronista da Gazeta de Notícias sugeriu que era "digno de nota o empenho que a diretoria do Fluminense 
Football Club tem tido pela educação de nossa mocidade", percebendo como se articulavam suas ações: "Além das várias seções esportivas de educação física, acaba de ser iniciada a prática da seção de escotismo (...) destinada não somente à cultura física, como à cívica, tão indispensável aos nossos jovens patriotas" (Correio da Manhã, 09 jan.1920, p. 6). Desejava, entusiasmado, o colunista: "oxalá o seu proceder seja imitado por todas as sociedades congêneres, pois o único meio de instruir física, moral e civicamente a nossa petizada é o escotismo, em que cada pequeno tem funções sérias e a convicção clara de suas obrigações".

$\mathrm{Na}$ Gazeta de Notícias, em 1924, foi elogiada uma vez mais a pujança da seção de escotismo do clube. De acordo com o articulista, o "aparelhamento existente para os escoteiros do Fluminense, é o mais completo possível e isto tem concorrido para o progresso sempre crescente dos grupos ali existentes" (Gazeta de Notícias, 19 jan. 1924 , p. 2).

Discursos em comum entre os líderes do movimento escoteiro e do campo esportivo, notadamente, abordavam dois aspectos - saúde e higiene da juventude, bem como defesa e glória da nação. Em novembro de 1924, realizou-se o Congresso das Municipalidades do Estado do Rio de Janeiro, com o intuito de organizar pautas políticas para o desenvolvimento local. No que tange ao tema "Melhoramento da raça", a tese única referia-se à questão "De como podem ser orientados e restringidos os esportes no sentido da eugenia?” (A.B.C., 22 nov. 1924, p. 20).

As conclusões do evento nos ajudam a vislumbrar como prática esportiva e escotismo eram tomados como estratégias articuladas. As orientações para desenvolver os dois foram tratadas num mesmo item. Claramente, tinha-se em conta as reflexões difundidas pelo movimento eugênico (Stepan, 2004), nos discursos se cruzando preocupações com saúde, higiene, desenvolvimento da raça.

Por ocasião da criação da seção de escotismo do Botafogo, ressaltou-se como motivação o fato de que "A educação ministrada aos nossos filhos nos colégios, com raras e honrosas exceções, age quase exclusivamente sobre a mentalidade das crianças e abandona a educação física"(A Noite, 12 jul.1922, p. 4). Para o cronista, isso deveria ser um investimento importante no intuito de forjar "homens fortes e bons", portadores de qualidades como "a lealdade, a coragem, sob todas as suas formas, o altruísmo, aconfiança em si, a responsabilidade, a disciplina voluntária, o respeito e obediência a seus pais, mestres e superiores, e uma série de outras, todas intimamente ligadas".

Percebemos uma constante celebração do corpo para o estabelecimento de um projeto de homem e de virilidade - embora já se começasse a discutir a participação das mulheres no esporte e no escotismo (Herold Junior e Vaz, 2013). Bem traduziu essa intencionalidade um cronista ao comentar a atuação de escoteiros do Botafogo em um acampamento, a seu ver algo que endossava o "valor incontestável da vida escoteira quer quanto a moral, quer quanto a virilidade e vigor físico da mocidade" (Correio da Manhã, 11 jan. 1927, p. 9).

Era posta em evidência a ideia de que os dois movimentos celebravam uma vida mais saudável pelo contato com a natureza, o que contribuiria para redimir o que chamavam de "decadência física". Sobre um acampamento realizado pelos escoteiros do Fluminense na cidade de Corrêas, Guilherme Azambuja Netto assim se pronunciou: 
Aqui estão, há dias, instalados em seu acampamento, gozando das delicias de uma vida passada em liberdade, fora das exigências do viver das cidades de grande movimento, cumulados de gentilezas de toda uma população que os festeja e acaricia os escoteiros do Fluminense Futebol Clube, os pequenos soldados da paz, parcela mínima deste exército valoroso que se formou sob a organização inspirada de Baden-Powell. (A Noite, 22 jan. 1923, p. 2)

Os acampamentos eram apresentados como oportunidades perfeitas para desenvolver nos jovens sua temperança física e moral, revertendo os maléficos efeitos do progresso e evitando que os jovens se desviassem para os vícios (Figura 6). Outro cronista comentou a iniciativa do seguinte modo:

Os meninos apresentam excelente físico e a melhor disposição de espírito; bastante queimados do sol, alegre e satisfeitos, tendo todos eles aumentado de peso e adquirido boas cores, o que vem provar, mais uma vez, as vantagens de um acampamento, nas condições em que este foi realizado. (A Noite, 07 fev. 1923, p. 5)

Houve manifestações ainda mais explícitas. Ao noticiar as comemorações do Dia do Escoteiro de 1923, o cronista da Gazeta de Notícias analisou os procedimentos metodológicos do escotismo. Ao enxergar no evento a "divulgação do esporte de Baden-Powell", assumido como "elemento aprimorador da raça", sugeriu:

Exercícios metodizados, nos quais se utilizam naturalmente as tendências pessoais para constituírem energias salutares, concorrem, na idade infantil, em que os temperamentos sujeitos às leis de evolução são facilmente modificáveis, para formação de indivíduos fortes pela resistência física e moral. O escoteiro convencido é sempre sadio: sabe amar a vida e cultuar a honra; [...] A lembrança de se comemorar hoje o "Dia do Escoteiro", vem evidenciar quão útil é o escotismo como elemento eugênico para formação de uma raça digna da perpetuidade

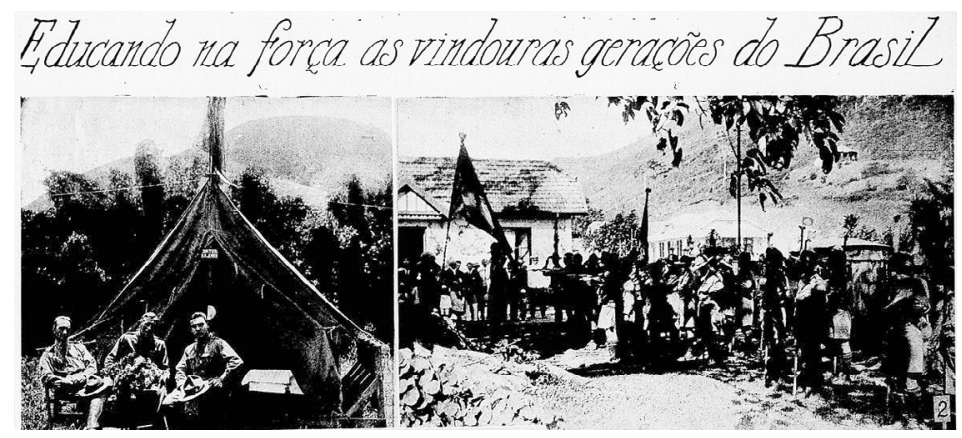

Figura 6 - Acampamento de escoteiros do Fluminense.

Fonte: Revista da Semana (3 fev. 1923, p. 31). 
de nossas tradições, de nossos usos e dos nossos costumes. (Gazeta de Notícias, 25 nov. 1923, p. 6)

"A postos, portanto, escoteiros do Fluminense: viremo-nos dentro em pouco cônscios do vosso papel no preparo para a vida de um cidadão útil a si mesmo e ao seu país" (Escotismo, 10 dez. 1919, p. 5): a conclamação eloquente do cronista é um exemplo de como o escotismo, assim como o esporte, foi também entendido como uma estratégia para glorificar a nação.

Os escoteiros de agremiações esportivas, comumente, participavam de cerimônias cívicas destinadas a comemorar datas consideradas importantes para o país. Alguns clubes passaram mesmo a acolher e promover tais eventos, como o que o Fluminense organizou, em 12 de junho de 1922, para recordar "um dos feitos mais brilhantes da nossa gente do mar: a batalha naval do Riachuelo" (A Noite, 12 jun. 1922, p. 6), travada em 1865. Coelho Neto concluiu sua fala solene com uma conclamação: “O Brasil espera que cada um cumpra seu dever!”.

Os símbolos nacionais eram exaltados nesses eventos, postura apresentada, ao mesmo tempo, como recurso formativo e como um dos benefícios do movimento. Numa matéria procurou-se explicar a atuação dos escoteiros do Botafogo. De início, apresentou-se uma síntese das principais atividades:

Os rapazes (de 11 a 18 anos) agrupados voluntariamente como escoteiros (com prévia autorização por escrito dos pais), recebem de instrutores solícitos e carinhosos toda a sorte de ensinamentos práticos, cívicos e morais, que são ministrados ao ar livre, em passeios pelos campos, em longas excursões, num regime de disciplina que é mais são do que qualquer outro, porque é voluntário. (A Noite 12 jul. 1922, p. 4)

Posteriormente, explicitaram-se os grandes princípios educativos, entre os quais a estrita observância das questões cívicas (Figura 7).

A educação do escoteiro começa ao iniciar ele a sua carreira, em que presta solenemente, diante dos seus companheiros, dos seus pais (que são sempre

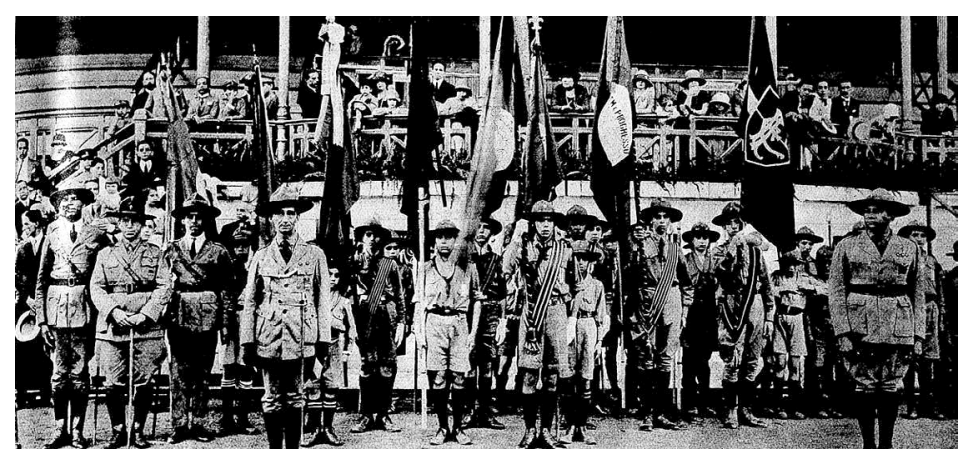

Figura 7 - Cerimônia Cívica no Flamengo, contando com escoteiros do clube, do Fluminense e do Botafogo. Fonte: Revista da Semana (13 out.1923, p. 28). 
convidados a assistir) e diante da bandeira, um juramento em cuja singela forma estão condensadas as qualidades morais e viris que se pode exigir num nobre caráter. (A Noite 12 jul. 1922, p. 4)

Nesse sentido, vale a pena ter em conta as palavras de Olavo Bilac, um dos grandes defensores tanto do escotismo quanto do esporte, no bojo de suas iniciativas e preocupações com o progresso da nação. $O$ poeta, na sua definição de movimento escoteiro, em vários momentos citou a importância da prática de atividades físicas e esportivas. $\mathrm{Na}$ sua visão, uma das funções mais relevantes dessas agremiações seria de "instrução física, a conservação e restabelecimento da saúde pela higiene e medicina, o desenvolvimento moral e progressivo de todas as funções do corpo, pela ginástica e pelos jogos escolares" (Almanaque do O Tico-Tico, 1926, p. 24). Para ele, "este curso completo de adestração é feito no seio da natureza, na alegria da vida esportiva".

Com efeito, na interpretação de numerosos cronistas, a nação precisava de corpos fortes e saudáveis, prontos para atitudes cívicas. Pela análise dos jornais, depreende-se que o esporte e escotismo eram considerados perfeitas estratégias para alcançar tal fim.

\section{CONCLUSÃO}

Em nossas reflexões procuramos discutir como escotismo e esporte dois importantes conjuntos de práticas e discursos formativos no início do século XX - estiveram articulados na cidade do Rio de Janeiro nas décadas de 1910 e 1920.

Vimos como foram recorrentes as iniciativas em comum. Facilmente perceptível, também, foi a frequência com que houve consonância nos discursos que pavimentaram caminhos formativos que levaram ao encontro o campo esportivo e o movimento escoteiro.

Tal articulação se deu em um contexto de grandes preocupações com a educação da juventude. As tensões pelas quais passava o país colocavam como imperiosa a demanda por respostas às questões internas, ladeadas por um quadro internacional marcado por crises e oposições de toda ordem, fornecendo terreno fértil para novas propostas de pedagogias corporais.

A frequência e a intensidade com que o esporte o escotismo foram objetos de interesse da imprensa carioca sinalizaram a relevância dessas iniciativas. Ainda que não diretamente relacionadas ao âmbito escolar, tais propostas estavam intrinsecamente articuladas com problemáticas educacionais que não podiam ignorar os limites específicos das escolas, apoiando-se na ênfase desses limites para destacar a urgência e correção daquilo que ofereciam como práticas.

Nesse cenário, o escotismo surgiu como uma possibilidade concreta de fomentar uma estratégia alternativa de formação. Algo semelhante aconteceu com o esporte, que se transformava e era engajado nas grandes questões do país. O encontro entre ambos gerou discursos que assumiram e propagaram a proximidade entre seus potenciais pedagógicos. 
O grande trunfo dessas práticas seria seu potencial para tratar questões relativas à educação corporal. Eram avaliadas como adequadas para desenvolver o senso de hierarquia, disciplina, rigor. Eram enaltecidas por sua capacidade de engajar crianças e jovens em torno de ideais tocantes ao contorno dos problemas do país nas primeiras décadas dos anos 1900 . Por essa razão, na miríade de vestígios encontrados e analisados, percebemos que dois grandes temas foram usualmente mobilizados nos encontros entre o movimento escoteiro e campo esportivo: a saúde e a higiene dos mais jovens, bem como a defesa da glória nacional. A partir de certo momento, essas dimensões se articularam com as propostas de aperfeiçoamento da raça, influência dos movimentos eugênicos.

Concluindo, a articulação entre discursos sobre o escotismo e sobre esporte evidencia que ao corpo e sua educação voltaram-se olhares inquietos com a turbulência dos anos 1910-1920. Inquietos, mas esperançosos com as possibilidades formativas dessas práticas. Inquietudes e esperanças a serem exploradas por pesquisadores interessados nas propostas de educação corporal que então floresciam.

\section{REFERÊNCIAS}

A.B.C. Congresso das Municipalidades do Estado do Rio de Janeiro. Rio de Janeiro, 22 nov. 1924, p. 20.

A Imprensa. Rio de Janeiro, 02 abr. 1911, p. 1.

Almanaque do o Tico-Tico. As palavras Olavo Bilac sobre o escoteirismo. Rio de Janeiro, 1926, p. 24.

A Noite. Os sports. Rio de Janeiro, 12 jun. 1922, p. 6.

. Para completar o desenvolvimento físico dos associados menores. Rio de Janeiro, 12 jul. 1922, p. 4.

. Discípulos de Baden-Powell. Rio de Janeiro, 22 jan. 1923, p. 2.

. Uma afirmação do escotismo brasileiro. Rio de Janeiro, 07 fev. 1923, p. 5.

. Escotismo. Rio de Janeiro, 24 nov. 1923, p. 7.

. Escotismo. Rio de Janeiro, 14 abr. 1926, p. 7.

. Escotismo. Rio de Janeiro, 16 out. 1927, p. 7.

A Rua. Rio também já possui escoteiros. Rio de Janeiro, 24 set. 1916, p. 1.

. Escotismo. Rio de Janeiro, 28 jun. 1923, p. 2.

Blower, B. D. A Marinha e o escotismo. Revista Maritima Brasileira, Rio de Janeiro, v. 115, n. 1/3, p. 59, jan.-mar. 1995.

Borba, C. Vida e obra do Almirante Benjamin Sodré. Revista Marítima Brasileira, Rio de Janeiro, v. 112, n. 10/12, p. 170, out.-dez. 1992.

Careta. Os boy-scouts na Espanha. Rio de Janeiro, 25 out. 1913, p. 25.

Carvalho, J. M. Forças armadas e política no Brasil. Rio de Janeiro: Zahar, 2005.

Coelno Neto. O escotismo. In: Guinle, A.; Pollo, M. Manual do escoteiro brasileiro. Rio de Janeiro: Imprensa Nacional, 1922. 
Correio da Manhã. Rio de Janeiro, 19 jun. 1910, p. 4.

. Exercícios de escotismo. Rio de Janeiro, 07 out. 1916, p. 5.

. Escotismo. Rio de Janeiro, 10 dez. 1919, p. 5.

. O escotismo no Fluminense. Rio de Janeiro, 09 jan. 1920, p. 6.

. Escotismo. Rio de Janeiro, 20 jun. 1920, p. 7.

. Escotismo. Rio de Janeiro, 23 out. 1923, p. 2.

. Vida escoteira - os primeiros passos do escotismo no Brasil. Rio de Janeiro, 11 dez. 1925, p. 10.

. Escotismo. Rio de Janeiro, 29 jan. 1926, p. 6.

. Escotismo. Rio de Janeiro, 11 jan. 1927, p. 9.

DÁvila, J.Diploma de brancura. Política social e racial no Brasil - 1917-1945. São Paulo: Editora Unesp, 2006.

Fernandez, R. L. Coelho Netto: um intelectual a serviço do esporte. Mosaico, Rio de Janeiro, v. 3, n. 5, p. 22-34, 2011.

. Ojogo da distinção: C. A. Paulistano e Fluminense F. C.: um estudo das identidades clubísticas durante a fase amadora do futebol em São Paulo e no Rio de Janeiro (19021933). 2016. 420f. Tese (Doutorado em História, Política e Bens Culturais) - Fundação Getúlio Vargas, Rio de Janeiro, 2016.

Ferreira,J.; Delgado, L. A. N. (Org.). O Brasil Republicano-O tempo do liberalismo excludente. Rio de Janeiro: Civilização Brasileira, 2003.

Gazeta de Notícias. Uma bela iniciativa do Fluminense Futebol Clube. Rio de Janeiro, 3 set. 1916, p. 7.

. O dia do Escoteiro. Rio de Janeiro, 25 nov. 1923, p. 6.

. Escotismo. Rio de Janeiro, 19 jun. 1924, p. 2.

Herold Junior, C. Corpo e educação no escotismo a partir da Revista O Tico-Tico (1921-1933). Movimento, Porto Alegre, v. 21, p. 303-316, 2015.

.; VAZ, A. F. Representações sobre corpo e educação da mulher na expansão do escotismo e do bandeirantismo durante as primeiras décadas do século XX. Revista Brasileira de Ciências do Esporte, Florianópolis, v. 35, p. 913-927, 2013. ; .Educação corporal, escotismo e militarismo (1908-1941). Movimento, Porto Alegre, v. 21, p. 1011-1023, 2015.

.; ___ Representações sobre o escotismo, o exército e a educação corporal no Brasil: um estudo a partir de teses apresentadas em Congressos Escoteiros (19221923). Movimento, Porto Alegre, v. 22, p. 417-430, 2016.

Jornal do Brasil. Escotismo. Rio de Janeiro, 23 fev. 1916, p. 10.

. Rio de Janeiro, 05 jun. 1917, p. 8.

Linhales, M. A. A escola e o esporte: uma história de práticas culturais. São Paulo: Editora Cortez, 2009. 
Luca, T. R. História dos, nos e por meio dos periódicos. In: Pinsky, C. B. (Org.). Fontes históricas. São Paulo: Ed. Contexto, 2005. p. 111-153.

Melo, V. A. Rio Esportivo. Rio de Janeiro: Casa da Palavra, 2015.

.; Peres, F. F. Esporte e modernidade: o caso do Rio de Janeiro - uma abordagem panorâmica. In: Melo, V. A. (Org.). O esporte no cenário Ibero-Americano. Rio de Janeiro: 7 Letras, 2015. p. 53-69. ; . Primórdios do esporte no Brasil - Rio de Janeiro. Manaus: Reggo Edições, 2016a. ;___ Primeiros ventos olímpicos em terras tupiniquins. Revista USP, São Paulo, n. 108, p. 39-48, jan.-mar. 2016b.

O Imparcial. Notas sociais. Rio de Janeiro, 12 fev. 1914, p. 5. . Registro Literário. Rio de Janeiro, 04 jan. 1917, p. 2. .Escotismo. Rio de Janeiro, 04 abr. 1921, p. 8.

O Malho. Rio de Janeiro, 17 set. 1910, p. 43. . Centro dos Boys Scouts do Brasil. Rio de Janeiro, 12 nov. 1911, p. 28. . Rio de Janeiro, 22 abr. 1922, p. 30. . Rio de Janeiro, 13 out. 1923.

O PAiz.Associação Brasileira de Escoteiros no Rio de Janeiro. Rio de Janeiro, 5 jun. 1917, p. 6. 1918, p. 10 . Ao Dr. Arnaldo Guinle foi oferecido ontem um almoço. Rio de Janeiro, 23 mar. . $1^{\circ}$ Congresso Fluminense de Desportos Terrestres. Rio de Janeiro, 11 ago. 1918, p. 12. .Escotismo. Rio de Janeiro, 15 mar. 1925, p. 13.

O Tico-Tico. Centro dos Boys Scouts do Brasil. Rio de Janeiro, 5 abr. 1911, p. 28. . Lawn-tennis. Rio de Janeiro, 22 dez. 1915, p. 12. . Sports d'O Tico-Tico. Rio de Janeiro, 26 dez. 1917, p. 11. . Associação de Escoteiros Católicos do Brasil. Rio de Janeiro, 17 jan. 1923, p. 16. . Noticiário. Rio de Janeiro, 16 mai. 1923, p. 17. . Escoteiros do C. R. Vasco da Gama. Rio de Janeiro, 3 ago. 1927, p. 14. . O torneio de Futebol da FEB. Rio de Janeiro, 9 nov. 1927, p. 21.

Revista DA Semana. Rio de Janeiro, 3 fev. 1923, p. 31.

. Rio de Janeiro, 13 out. 1923, p. 28.

SOAREs, C. L. Corpo, Conhecimento e Educação: notas esparsas. In: (Org.). Corpo e História. Campinas: Autores Associados, 2001. p. 109-129.

Stepan, N. L. Eugenia no Brasil, 1917-1940. In: Hochman, G.; Armus, D. (Orgs.). Cuidar, controlar, curar: ensaios históricos sobre saúde e doença na América Latina e Caribe. Rio de Janeiro: Editora Fiocruz, 2004.

Vigarello, G. A história e os modelos do corpo. Pró-posições, Campinas, v. 14, n. 2, p. 21-29, mai.-ago. 2003. 


\section{SOBRE OS AUTORES}

Carlos Herold Junior é doutor em educação pela Universidade Federal do Paraná (UFPR). Professor da Universidade Estadual de Maringá (UEM). E-mail: carlosherold@hotmail.com

Victor Andrade De Melo é doutor em educação pela Universidade Gama Filho (UGF). Professor da Universidade Federal do Rio de Janeiro (UFRJ). E-mail: victor.a.melo@uol.com.br

Recebido em 13 de janeiro de 2017 Aprovado em 27 de abril de 2017 